\title{
PARENTERAL ANTIBIOTIC USAGE PATTERNS AND EFFECTS OF INTRAVENOUS TO ORAL SWITCHING ON THE LENGTH AND COST OF HOSPITALIZATION
}

\author{
RENGGANIS PRANANDARI ${ }^{1}$, SUDIBYO SUPARDI ${ }^{2}$, RETNOSARI ANDRAJATI ${ }^{1 *}$
}

${ }^{1}$ Department of Clinical Pharmacy, Faculty of Pharmacy, Universitas Indonesia, Depok, Indonesia. ${ }^{2}$ Centre of Public Health Intervention Technology, Agency for Health Research and Development, Ministry of Health, Indonesia. Email: andrajati@farmasi.ui.ac.id

Received: 21 April 2017, Revised and Accepted: 13 July 2017

\section{ABSTRACT}

Objective: The prolonged use of intravenous antibiotics might increase the length and cost of hospitalization. The research objective, therefore, was to evaluate the effect of switching antibiotics on the length of hospital stay and hospitalization cost. The prospective cohort research design was adopted. The inclusion criteria were in patients who had received intravenous antibiotics.

Methods: The sample comprised 39 patients who switched antibiotics as an exposed group and 39 patients who did not switch as an unexposed group. The data were collected using the patient medical records and the financial data from the hospital information system. The Mann-Whitney test and Chi-square or Fisher's exact test was applied in the analysis.

Results: The results revealed that the antibiotics most commonly switched were intravenous ceftriaxone (83.3\%) and oral cefixime (94.8\%). From the five switching patterns observed, the most common switch was from intravenous ceftriaxone to oral cefixime in patients with acute gastroenteritis. All antibiotics were administered in accordance with the National Formulary (NF) guidelines. Only metronidazole (5 mg/ml dose) was inconsistent with NF. Switching antibiotics did not impact the length of hospital stay and hospitalization cost; however, comorbidities did have an influence here.

Conclusions: Further, switching antibiotics impacted the duration over which intravenous antibiotics were administered and the cost of antibiotics.

Keywords: Switching antibiotics, Length of stay, Cost.

(C) 2017 The Authors. Published by Innovare Academic Sciences Pvt Ltd. This is an open access article under the CCBY license (http://creativecommons. org/licenses/by/4. 0/) DOI: http://dx.doi.org/10.22159/ijap.2017.v9s1.44_50

\section{INTRODUCTION}

Infectious diseases are still one of the most important public health issues, especially in developing countries [1]. In developing countries, $44-97 \%$ of hospital patients are prescribed antibiotics [2]. Dispensing antibiotic without prescription is illegal and alarming; therefore, improvement on the current prescribing pattern for both prescribers and pharmacists is highly warranted [3]. Research on two educational hospitals in Indonesia showed that $84 \%$ of patients received antibiotics [2]. Further, $62 \%$ of all antibiotics prescribed are administered intravenously [2]. Antibiotics are usually administered intravenously at the beginning of hospitalization to provide optimal concentration [4]. About one-third of patients receiving antibiotics intravenously are eligible for switching to oral antibiotics $[5,6]$.

Several studies have shown that antibiotics are often prescribed intravenously even if patients may be taking oral antibiotics [7]. If antibiotics are not switched at the right time, the cost of treatment increases [7]. Further, the duration of intravenous antibiotics is a major factor affecting the length of hospitalization, which is a chief determinant of hospital costs $[4,8]$. Patients receiving intravenous antibiotics often undergo prolonged hospitalization so that antibiotic treatment can be completed. Intravenous to oral switching may facilitate earlier patient repatriation and save maintenance costs [9]. The economic pressures are facing the hospital result in the length of stay being reduced and an increased interest in switching as well as the early discharge of patients [8].

Several studies have demonstrated that implementing switching therapy for patients requiring intravenous antibiotics successfully decreases the length of stay [10]. Switching antibiotics have been shown to significantly reduce hospital costs without sacrificing effectiveness or safety [11]. This phenomenon was observed in Depok General Hospital (DGH), the only government-owned hospital in Depok City, Indonesia. Due to the lack of hospitals in cooperation with the
Social Security Administration Agency in Depok City, a large number of patients under National Health Insurance were referred to DGH. DGH is a Type C hospital with 71 beds for patient services. As DGH does not have microbiology laboratory, antibiotic therapy is empirically supported [12]. Given the limited information of antibiotic use at DGH, this work studied parenteral antibiotic usage patterns and the effect of intravenous to oral switching on the length of stay and hospitalization cost at DGH. The objective of this study was to evaluate the effect of antibiotic switching on the duration of stay and cost of patient hospitalization in DGH as well as to evaluate compliance with National Formulation (NF) guidelines.

\section{METHODS}

A prospective cohort study design was adopted, where antibiotic switching was performed during the treatment in the exposed group and antibiotics were not switched in the unexposed group. The inclusion criteria were patients aged 18 years and older, in internal medicine, neurology, and in isolation at DGH, who received antibiotics intravenously at the beginning of their treatment. The exclusion criteria were patients who presented incomplete data. This study assessed the effect of the independent variable, namely, antibiotic switching, to the dependent variables of length of hospitalization stay and inpatient costs, considering age, body mass index (BMI), comorbidity, and payment status as the confounding variables.

Medical data and patient treatment were prospectively taken from medical records. The data collected included the patients' medical record number, name, age, gender, payment status, height and weight, diagnosis, prior disease history, current disease history, comorbidities, antibiotic regimens, clinical signs of patients, laboratory data and radiological examination, treatment class, length of hospitalization stay, and duration of intravenous antibiotics. Financial data were obtained from the hospital information system at DGH. These data include antibiotic costs, action costs (e.g., injection, infusion, nasogastric 
tubes and urine bags, and oxygen delivery), support costs (laboratory, radiological, and other examinations), maintenance costs (nursing room and doctor visits), and the cost of other drugs and medical devices.

The data were statistically analyzed using the SPSS program. Univariate analysis was performed to obtain a picture of the frequency distribution of the variables studied, such as patient characteristics, antibiotic characteristics, the normality test of old data, and hospitalization costs. The Chi-square test or Fisher test was performed to assess the equality of confounding variables between the switching and non-switching groups. The Mann-Whitney test was conducted to assess the effect of the confounding variables on the dependent variables and the influence of the independent variable on dependent variables. Linear regression was used for the multivariate analysis.

\section{RESULTS}

There were 119 samples, comprising 44 patients in the switching group and 75 patients in the non-switching group. Four patients were excluded and 14 patients failed to follow-up. A simple random sampling was performed in the non-switching group to equalize the numbers between the two groups, such that 39 patients were obtained for each group. The patient characteristics are shown in Table 1, presenting the highest percentages in terms of gender, age, non-underweight, comorbidity (diagnosis of individual comorbidities ranging from 1 to 4 types of conditions), insurance payment status, and Class 3 care facilities. The patients were categorized on the basis of age group into adults-young adults between 19 and 49 years of age and adults between 50 and 64 years of age-and the elderly, namely, those who were 65 years and above [13]. The BMI group was categorized based on the criteria used for the Asian population: Underweight being below $18 \mathrm{~kg} / \mathrm{m}^{2}$, non-underweight-comprising normal-weight patients between 18 and $22.9 \mathrm{~kg} / \mathrm{m}^{2}$ and overweight patients between 23 and $24.9 \mathrm{~kg} / \mathrm{m}^{2}$ - and obese being above $25 \mathrm{~kg} / \mathrm{m}^{2}[14]$.

The Chi-square or Fisher's exact test was performed to determine the equality of age, BMI, comorbidity, and payment status between the switching and non-switching groups. The results of this equality test are presented in Table 2 .

The test results showed that there was no difference in the characteristics of patients between the switching and non-switching groups $(p>0.05)$. As DGH does not have a microbiology laboratory and Diagnosis Therapy Guidance (PDT), all antibiotics are administered empirically on the basis of each physician's experience. Table 3 summarizes the characteristics of antibiotics used in switching. The most commonly administered intravenous antibiotic is ceftriaxone (83.3\%), followed by cefotaxime $(6.4 \%)$.

Cefixime (94.8\%) is the most commonly switched oral antibiotic from intravenous antibiotics. Cefixime is an oral third-generation cephalosporin antibiotic that shows antimicrobial activity against both Gram-positive and negative bacteria, including Enterobacteriaceae. On oral administration, nearly 50\% immediately reach bactericidal concentrations and penetrate tissues well [2]. Table 4 summarizes the switching patterns from intravenous to oral antibiotics.

Doctors prescribe switching for a number of reasons: The patient could be free of fever, the clinical conditions could have improved, and the patient may be able to consume the oral medication. Each doctor has a different switching policy. Some doctors prescribe switching on the $5^{\text {th }}$ day of intravenous use of antibiotics. There are also doctors who prescribe switching based on the patient's clinical conditions, such that it is done earlier. Some studies suggest that the optimal time for switching is the $2^{\text {nd }}$ to $4^{\text {th }}$ day of intravenous antibiotics $[6,15,16]$. The study did not observe any patients who relapsed or required intravenous antibiotics again after switching. Table 5 summarizes the switching of antibiotics based on the diagnosis.

Most intravenous antibiotics are used in the treatment of acute gastroenteritis (AGE) (37.2\%), leukocytosis (19.2\%), typhoid (15.4\%),
Table 1: Patients' characteristics

\begin{tabular}{|c|c|c|c|}
\hline Characteristics & Switching & Non-switching & Total (\%) \\
\hline \multicolumn{4}{|l|}{ Gender } \\
\hline Male & 16 & 19 & 35 (44.9) \\
\hline Female & 23 & 20 & $43(55.1)$ \\
\hline Total & 39 & 39 & $78(100.0)$ \\
\hline \multicolumn{4}{|l|}{ Comorbidity diagnosis } \\
\hline Dengue hemorrhagic fever & 11 & 3 & $14(20.3)$ \\
\hline Congestive heart failure & 0 & 5 & $5(7.2)$ \\
\hline Dyspepsia & 2 & 2 & $4(5.8)$ \\
\hline Others & 23 & 23 & $46(66.7)$ \\
\hline Total & 36 & 33 & $69(100.0)$ \\
\hline \multicolumn{4}{|l|}{ Class } \\
\hline Class 2 & 4 & 7 & $11(14.1)$ \\
\hline Class 3 & 35 & 32 & $67(85.9)$ \\
\hline Total & 39 & 39 & $78(100.0)$ \\
\hline
\end{tabular}

Table 2: Equality test for the confounding variables between the switching and non-switching groups of infectious patients

\begin{tabular}{|c|c|c|c|}
\hline \multirow[t]{2}{*}{ Variables } & \multicolumn{2}{|l|}{ n (\%) } & \multirow[t]{2}{*}{ p value } \\
\hline & Switching & Non-switching & \\
\hline \multicolumn{4}{|l|}{ Age } \\
\hline Adult & $32(82.1)$ & $33(84.6)$ & $0.761^{\mathrm{a}}$ \\
\hline Elderly & $7(17.9)$ & $6(15.4)$ & \\
\hline Total & $39(100)$ & $39(100)$ & \\
\hline \multicolumn{4}{|l|}{ BMI } \\
\hline Underweight & $4(10.3)$ & 7 (17.9) & $0.329^{a}$ \\
\hline Not underweight & 35 (89.7) & $32(82.1)$ & \\
\hline Total & $39(100)$ & $39(100)$ & \\
\hline \multicolumn{4}{|l|}{ Comorbidity } \\
\hline Present & $36(92.3)$ & $33(84.6)$ & $0.481^{\mathrm{b}}$ \\
\hline None & $2(7.7)$ & $4(15.4)$ & \\
\hline Total & $39(100)$ & $39(100)$ & \\
\hline \multicolumn{4}{|l|}{ Payment methods } \\
\hline Assurance & $33(84.6)$ & $30(76.9)$ & $0.389^{a}$ \\
\hline Non-assurance & $6(15.4)$ & $9(23.1)$ & \\
\hline Total & $39(100)$ & $39(100)$ & \\
\hline
\end{tabular}

Table 3: Characteristics of antibiotics

\begin{tabular}{ll}
\hline Antibiotic & Total number of patients (\%) \\
\hline Intravenous & $2(2.6)$ \\
Levofloxacin & $1(1.3)$ \\
Levofloxacin+metronidazole & $1(1.3)$ \\
Levofloxacin+ceftriaxone & $5(6.4)$ \\
Cefotaxime & $1(1.3)$ \\
Ceftazidime & $65(83.3)$ \\
Ceftriaxone & $1(1.3)$ \\
Ceftriaxone/levofloxacin & $2(2.5)$ \\
Ceftriaxone+metronidazole & $78(100)$ \\
Total & \\
Oral & $37(94.8)$ \\
Cefixime & $1(2.6)$ \\
Ciprofloxacin & $1(2.6)$ \\
Ciprofloxacin+cefixime & $39(100.0)$ \\
Total &
\end{tabular}

+ - Represents combination,/- Indicates a switching antibiotic

and urinary tract infections (11.5\%). According to the 2013 profile data of DGH, age ranks second among the top 10 diseases in the inpatient unit, followed by typhoid.

Most of the switching was performed in the case of AGE (16 persons) and typhoid (10 people) patients. Most of the research on switching is limited to antibiotics or certain medical conditions, such as community pneumonia. Only a few studies have evaluated switching in the general 
Table 4: Switching pattern from intravenous to oral antibiotics

\begin{tabular}{|c|c|c|c|}
\hline Diagnosis & Intravenous & Oral & Total \\
\hline Bronchitis & Ceftriaxone & Cefixime & 1 \\
\hline Fever & Ceftriaxone & Cefixime & 2 \\
\hline AGE & Ceftriaxone & Cefixime & 16 \\
\hline \multirow[t]{4}{*}{ UTI } & Cefotaxime & Cefixime & 1 \\
\hline & Ceftriaxone & Cefixime & 1 \\
\hline & Levofloxacin & Ciprofloxacin & 1 \\
\hline & Ceftriaxone & Ciprofloxacin+cefixime & 1 \\
\hline \multirow[t]{3}{*}{ Suspect tuberculosis typhoid } & Ceftriaxone & Cefixime & 1 \\
\hline & Ceftriaxone & Cefixime & 9 \\
\hline & Ceftriaxone + metronidazole & Cefixime & 1 \\
\hline Total & & & 39 \\
\hline
\end{tabular}

+ - Indicates combination. UTI: Urinary tract infection, AGE: Acute gastroenteritis

population of patients. These studies reported that switching was most common in patients with respiratory infections $[5,6,15]$.

Switching was not performed in the case of patients with septic shock. This contrasts with the study by Mertz et al., which states that sepsis patients who switch to oral ciprofloxacin develop a fever again [15]. Further, monitoring of these patients indicated multiple liver abscesses. The patients recovered after continuing with intravenous antibiotic therapy.

DGH has implemented the National Health Insurance Program and adopted the NF guidelines as a reference for drug use. The suitability of antibiotic usage is assumed to be based on knowledge of drug selection based on guidelines established by both NF and the formulary of DGH, 2013-2014. Table 6 summarizes data pertaining to the conformity of antibiotic usage with the NF guidelines and the formulary of DGH.

Table 6 summarizes all the antibiotics used in accordance with NF. One antibiotic is shown to be incompatible with the formulary of DGH 20132014, namely, metronidazole $5 \mathrm{mg} / \mathrm{ml}$. This is a good indication, implying that doctors have complied with both NF and the formulary of DGH, in addition to ensuring that the patient receives the medication prescribed by the hospital. The Kolmogorov-Smirnov test for normality showed that the distribution of inpatients and inpatient costs was not normal $(\mathrm{p}<0.05)$. Table 7 summarizes the Mann-Whitney test results pertaining to the effect of the confounding variables on the duration of stay and inpatient costs.

The test results are used to determine the confounding variables to be tested for influence on the dependent variable (length of stay and cost) along with the independent variables (antibiotic switching), using linear regression. The variables to be included in the linear regression analysis are those for which the bivariate analysis has a $\mathrm{p}<0.25$, namely, comorbidity and payment status. The Mann-Whitney test is used to determine the effect of switching on the duration and cost of patient hospitalization. Table 8 summarizes the test results.

However, with the Mann-Whitney test, the change was not significant $(p>0.05)$. Table 9 summarizes the results of the multivariate linear regression test between the independent variable (antibiotic switching), the dependent variables (duration and hospitalization cost), and the confounding factors (comorbidity and payment status). Further, Table 10 summarizes the effect of switching on the duration of intravenous antibiotics and antibiotic costs.

The average duration of intravenous antibiotics decreased significantly $(p=0.000)$ from 5.67 days (non-switching group) to 3.49 days (switching group). Further, the average cost of antibiotics decreased significantly ( $p=0.003$ ) from Rp. 114,781.28 (non-switching group) to Rp. 46,478.21 (switching group).

\section{DISCUSSION}

The results showed that comorbidity had an effect on the length of stay and hospitalization cost. Comorbidities result in a lengthier hospital
Table 5: Switching antibiotics based on diagnosis

\begin{tabular}{llll}
\hline Diagnosis & Switching & Non-switching & Total (\%) \\
\hline Bronchitis & 1 & 1 & $2(2.6)$ \\
Bronchopneumonia, & 0 & 5 & $5(6.4)$ \\
UTI & & & \\
Fever & 0 & 1 & $1(1.3)$ \\
AGE & 2 & 1 & $3(3.8)$ \\
UTI & 16 & 13 & $29(37.2)$ \\
Leukocytosis & 4 & 5 & $9(11.5)$ \\
Suspect tuberculosis & 5 & 10 & $15(19.2)$ \\
Shock sepsis & 1 & 0 & $1(1.3)$ \\
Typhoid & 0 & 1 & $1(1.3)$ \\
& 10 & 2 & $12(15.4)$ \\
Total & 39 & 39 & $78(100.0)$ \\
\hline
\end{tabular}

UTI: Urinary tract infection, AGE: Acute gastroenteritis

Table 6: Compliance of antibiotics usage with NF guidelines and the formulary of DGH

\begin{tabular}{lll}
\hline Antibiotic & NF & Formulary of DGH, 2013-2014 \\
\hline Levofloxacin $5 \mathrm{mg} / \mathrm{ml}$ & $\mathrm{V}$ & $\mathrm{V}$ \\
Metronidazole $5 \mathrm{mg} / \mathrm{ml}$ & $\mathrm{V}$ & - \\
Cefixime $100 \mathrm{mg}$ capsule & $\mathrm{V}$ & $\mathrm{V}$ \\
Cefotaxime $1 \mathrm{~g}$ & $\mathrm{~V}$ & $\mathrm{~V}$ \\
Ceftazidime $1 \mathrm{~g}$ & $\mathrm{~V}$ & $\mathrm{~V}$ \\
Ceftriaxone $1 \mathrm{~g}$ & $\mathrm{~V}$ & $\mathrm{~V}$ \\
Ciprofloxacin $500 \mathrm{mg}$ tablet & $\mathrm{V}$ & $\mathrm{V}$
\end{tabular}

V represents a match, - indicates no match, DGH: Depok General Hospital, NF: National Formulary

stay and higher hospitalization costs. This relationship can be explained in terms of the time needed to care for and address the patient's illness. The more the diseases, the longer the treatment [17], and the higher the cost of hospitalization.

According to the previous research on the use of antibiotics, the most frequently used antibiotics were ceftriaxone (31.43\%), followed by cefotaxime (20.95\%) [18]. These are third-generation cephalosporin antibiotics, which have been widely used in the treatment of various infectious diseases caused by a broad-spectrum of antibacterial activity, including Gram-negative and Gram-positive bacteria.

Switching can significantly reduce the duration over which intravenous antibiotics are administered, but it does not reduce the length of hospitalization, which is influenced by comorbidity and payment status. Thus, even in the case of switching, the patient is notimmediately discharged because overcoming comorbidity takes some time. A meta-analysis reported that five studies used specific criteria for returning patients in addition to switching, including no comorbid treatment or diagnostic examination requirements [8]. According to Mandell et al., patients can 
Table 7: The effect of confounding variables on the length of hospitalization and cost of treatment

\begin{tabular}{|c|c|c|c|c|}
\hline Variables & $\mathbf{n}$ & Mean & $\begin{array}{l}\text { Standard } \\
\text { deviation }\end{array}$ & p \\
\hline \multicolumn{5}{|l|}{$\begin{array}{l}\text { Length of } \\
\text { hospitalization (davs) }\end{array}$} \\
\hline \multicolumn{5}{|l|}{ Age } \\
\hline Adult & 65 & $5.69 \sim 6$ & 2.24 & \multirow[t]{2}{*}{0.591} \\
\hline Elderly & 13 & $5.92 \sim 6$ & 2.18 & \\
\hline \multicolumn{5}{|l|}{ BMI } \\
\hline Underweight & 11 & $5.91 \sim 6$ & 2.62 & \multirow[t]{2}{*}{0.907} \\
\hline Not underweight & 67 & $5.70 \sim 6$ & 2.17 & \\
\hline \multicolumn{5}{|l|}{ Comorbidity } \\
\hline Present & 69 & $6.01 \sim 6$ & 2.19 & \multirow[t]{2}{*}{0.000} \\
\hline None & 9 & $3.56 \sim 4$ & 0.73 & \\
\hline \multicolumn{5}{|l|}{ Payment methods } \\
\hline Assurance & 63 & $5.95 \sim 6$ & 2.29 & \multirow[t]{2}{*}{0.052} \\
\hline Non-assurance & 15 & $4.80 \sim 5$ & 1.66 & \\
\hline \multicolumn{5}{|l|}{ Cost (rupiah) } \\
\hline \multicolumn{5}{|l|}{ Age } \\
\hline Adult & 65 & 2621.780 & 1849.116 & \multirow[t]{2}{*}{0.433} \\
\hline Elderly & 13 & 2832.572 & 1408.100 & \\
\hline \multicolumn{5}{|l|}{ BMI } \\
\hline Underweight & 11 & 2806.242 & 1621.443 & \multirow[t]{2}{*}{0.651} \\
\hline Not underweight & 67 & 2632.396 & 1811.281 & \\
\hline \multicolumn{5}{|l|}{ Comorbidity } \\
\hline Present & 69 & 2874.471 & 1774.747 & \multirow[t]{2}{*}{0.000} \\
\hline None & 9 & 988.959 & 278.168 & \\
\hline \multicolumn{5}{|l|}{ Payment methods } \\
\hline Assurance & 63 & 2739.944 & 1679.054 & \multirow[t]{2}{*}{0.109} \\
\hline Non-assurance & 15 & 2308.181 & 2172.142 & \\
\hline
\end{tabular}

BMI: Body mass index

Table 8: Effect of switching on the length of stay and cost of treatment

\begin{tabular}{lllll}
\hline Variables & $\mathbf{n}$ & Mean & $\begin{array}{l}\text { Standard } \\
\text { deviation }\end{array}$ & $\mathbf{p}$ \\
\hline Length (day) & & & & \\
$\quad$ Switching group & 39 & $5.56 \sim 6$ & 2.1 & 0.619 \\
$\quad$ Non-switching group & 39 & $5.89 \sim 6$ & 2.35 & \\
Cost (rupiah) & & & & 0.475 \\
$\quad$ Switching group & 39 & 2400.980 & 1340.565 & \\
$\quad$ Non-switching group & 39 & 2912.844 & 2113.276 & \\
\hline
\end{tabular}

be discharged as soon as their clinical condition is stable, they present no active medical problems, and have a safe environment in which to continue therapy [19]. Switching can also reduce the cost of antibiotics significantly but does not reduce hospitalization costs. This is due to the presence of comorbidities. Thus, even though the cost of antibiotics is reduced, other drug costs are still incurred through actions, support, and treatments taken to combat the comorbidities. The results of this study are consistent with some previous works. For example, according to a study in Switzerland [9], the use of checklists as a reminder of the criteria for intravenous oral antibiotic switching may significantly reduce the duration of intravenous antibiotics. However, the decrease in the length of hospitalization was not found to be statistically significant. A retrospective observational study in Lebanon [6] reported that the duration of intravenous antibiotics administered in the switching group was shorter than that in the nonswitching group. The length of hospitalization in the switching group was shorter than in the switching group, but these results were not significant either. Different results were found in a study on antibiotic switching in severe community-acquired pneumonia patients in the Netherlands. The study reported that switching antibiotics can significantly reduce the duration of intravenous administration and the length of hospitalization.

Suggestions for further research include the need to examine the role of clinical pharmacists in intravenous to oral switching of antibiotics
Table 9: Relationship between independent variables, dependent variables, and confounding variables with respect to patients' treatment

\begin{tabular}{lllll}
\hline Variables & B & Beta & $\mathbf{p}$ & $\mathbf{R}^{2}$ \\
\hline Duration & & & & \\
$\quad$ Comorbidity & -2.422 & -0.351 & 0.001 & 0.165 \\
$\quad$ Payment status & -1.099 & -0.196 & 0.067 & \\
Cost & & & & \\
$\quad$ Antibiotic switching & $66,6563.58$ & 0.189 & 0.082 & 0.152 \\
$\quad$ Comorbidity & -2.011 & -0.364 & 0.001 & \\
\hline
\end{tabular}

Table 10: The effects of switching against the length and cost of using antibiotics among patients

\begin{tabular}{lllll}
\hline Variables & n & Mean & $\begin{array}{l}\text { Standard } \\
\text { deviation }\end{array}$ & p \\
\hline $\begin{array}{l}\text { Duration (day) } \\
\quad \text { Switching group }\end{array}$ & 39 & 3.49 & 1.19 & 0.000 \\
$\quad$ Non-switching group & 39 & 5.67 & 2.33 & \\
$\quad \begin{array}{l}\text { Cost (rupiah) } \\
\quad \text { Switching group }\end{array}$ & 39 & 46.478 & 51.947 & 0.003 \\
$\quad$ Non-switching group & 39 & 114.781 & 169.660 & \\
\hline
\end{tabular}

and the effects of switching in decreasing the length and cost of patient hospitalization. Future, studies should also research switching by limiting the type of antibiotics, medical conditions, or duration of intravenous antibiotics. A recommendation for DGH is to prepare a set of guidelines for the prescription and administration of antibiotics. Pharmacists in DGH should be alert and prevent the excessive administration of intravenous antibiotics.

\section{CONCLUSION}

The most common antibiotics used for switching were intravenous ceftriaxone and oral cefixime. Five switching patterns were observed, most commonly from intravenously administering ceftriaxone to orally administering cefixime in patients with AGE. All antibiotics were used in accordance with the NF guidelines, although one antibiotic (metronidazole $5 \mathrm{mg} / \mathrm{ml}$ ) was found to be incompatible with the guidelines of the formulary of DGH. Switching antibiotics was found to have no significant effect on the duration and cost of hospitalization among patients at DGH, although comorbidity did have a significant effect. Switching antibiotics only affects the duration over which they are administered and their cost

\section{REFERENCES}

1. Peraturan Menteri Kesehatan RI No. 2406/Menkes/Per/XII/2011. Tentang Pedoman Umum Penggunaan Antibiotik.

2. Hadinegoro SR, Tumbelaka AR, Satari HI. Pengobatan cefixime pada demam tifoid anak. Sari Pediatr 2001;2(4):182-7.

3. Abasaeed AE, Vlcek J, Abuelkhair MA, Andrajati R, Elnour AA. A comparative study between prescribed and over-the-counter antibiotics. Saudi Med J 2013;34(10):1048-54.

4. Oosterheert JJ, Bonten MJ, Schneider MM, Buskens E, Lammers JW, Hustinx WM, et al. Effectiveness of early switch from intravenous to oral antibiotics in severe community acquired pneumonia: Multicentre randomised trial. BMJ 2006;333(7580):1193.

5. McLaughlin CM, Bodasing N, Boyter AC, Fenelon C, Fox JG, Seaton RA. Pharmacy-implemented guidelines on switching from intravenous to oral antibiotics: An intervention study. QJM 2005;98(10):745-52.

6. Shrayteh ZM, Rahal MK, Malaeb DN. Practice of switch from intravenous to oral antibiotics. Springerplus 2014;3:717.

7. Ho BP, Lau TT, Balen RM, Naumann TL, Jewesson PJ. The impact of a pharmacist-managed dosage form conversion service on ciprofloxacin usage at a major Canadian teaching hospital: A pre-and post-intervention study. BMC Health Serv Res 2005;5:48.

8. Rhew DC, Tu GS, Ofman J, Henning JM, Richards MS, Weingarten SR. 
Early switch and early discharge strategies in patients with community-acquired pneumonia: A meta-analysis. Arch Intern Med 2001;161(5):722-7.

9. Di Giammarino L, Bihl F, Bissig M, Bernasconi B, Cerny A, Bernasconi E. Evaluation of prescription practices of antibiotics in a medium-sized Swiss hospital. Swiss Med Wkly 2005;135(47-48):710-4.

10. Dunn K, O'Reilly A, Silke B, Rogers T, Bergin C. Implementing a pharmacist-led sequential antimicrobial therapy strategy: A controlled before-and-after study. Int J Clin Pharm 2011;33(2):208-14.

11. Davis SL, Delgado G, McKinnon PS. Pharmacoeconomic considerations associated with the use of intravenous-to-oral moxifloxacin for community-acquired pneumonia. Clin Infect Dis 2005;41 Suppl 2:S136-43.

12. RSUD Kota Depok. Buku Profil RSUD Kota Depok 2013. Depok: RSUD Kota Depok; 2013

13. Almatsier S, Soetardjo S, Soekatri M. Gizi Seimbang Dalam Daur Kehidupan. Jakarta: Gramedia Pustaka Utama; 2011.

14. Low S, Chin MC, Ma S, Heng D, Deurenberg-Yap M. Rationale for redefining obesity in Asians. Ann Acad Med Singapore 2009;38(1):66-9.

15. Mertz D, Koller M, Haller P, Lampert ML, Plagge H, Hug B, et al.
Outcomes of early switching from intravenous to oral antibiotics on medical wards. J Antimicrob Chemother 2009;64(1):188-99.

16. Senn L, Burnand B, Francioli P, Zanetti G. Improving appropriateness of antibiotic therapy: Randomized trial of an intervention to foster reassessment of prescription after 3 days. J Antimicrob Chemother 2004;53(6):1062-7.

17. Kuwabara K, Imanaka Y, Matsuda S, Fushimi K, Hashimoto H, Ishikawa KB, et al. The association of the number of comorbidities and complications with length of stay, hospital mortality and LOS high outlier, based on administrative data. Environ Health Prev Med 2008;13(3):130-7.

18. Lestari W. Studi Penggunaan Antibiotik berdasarkan Sistem ATC/DDD dan Kriteria Gyysens di Bangsal Penyakit Dalam RSUP DR.M.D Jamil Padang [Thesis]. Padang: Universitas Andalas; 2011.

19. Mandell LA, Wunderink RG, Anzueto A, Bartlett JG, Campbell GD, Dean NC, et al. Infectious Diseases Society of America/American Thoracic Society consensus guidelines on the management of community-acquired pneumonia in adults. Clin Infect Dis 2007;44 Suppl 2:S27-72 